\title{
Definition and Risk Factors for anovulation Diagnosed at 50 Days in Milk in Dairy Cows
}

\author{
J. Dubuc* \\ Université de Montréal, Rue Sicotte, Faculté de médecine vétérinaire, Saint-Hyacinthe, Québec, Canada
}

Received: 眥 May 07, 2018; Published: 㘹 May 21, 2018

*Corresponding author: Jocelyn Dubuc, Faculté de médecine vétérinaire, Université de Montréal, Saint-Hyacinthe, Québec, Canada

\begin{abstract}
The objectives of this observational study were to determine the optimal progesteronemia threshold for defining anovulation at 50 days in milk (DIM) in dairy cows and to identify risk factors for this condition. A total of 3,776 cows from 100 Holstein dairy herds were enrolled in this cow-level study. During farm visits, cows were bled at 1-14DIM to quantify ketonemia and glycemia, examined at 30-43 DIM to diagnose purulent vaginal discharge, cytological endometritis, and leukocyte esterase endometritis, and were bled at a 14d interval to quantify progesteronemia. Multiple progesteronemia thresholds were tested to identify the one providing the highest sum of sensitivity and specificity to predict the pregnancy status at first service. The optimal threshold found for defining anovulation at 50DIM was $\leq 0.90 \mathrm{ng} / \mathrm{mL}$. The final model for risk factors included parity group, season of calving, cytological endometritis, hyperketonemia, hypoglycemia, and the two-way interaction term of hyperketonemia and hypoglycemia. Overall, these results suggest that a progesteronemia threshold of $\leq 0.9 \mathrm{ng} / \mathrm{mL}$ could be used to define anovulation at 50 days in milk in dairy cows.
\end{abstract}

Keywords: Dairy Cow; Anovulation; Postpartum Period; Risk Factor; Progesterone Concentrations; Metritis; Endometritis; Parity; Season; Placenta

\section{Introduction}

Cows with early resumption of ovarian cyclicity during the postpartum period were shown to have better subsequent reproductive performance than cows with postpartum anovulation [1-3]. In fact, data showed that cycling as soon as 21DIM is associated with improved reproductive performance compared to cows that start cycling later but before 63DIM; the latter cows have a better performance than cows that started to cycle after 63DIM $[2,4]$. Therefore, postpartum anovulation is an important condition to consider during the postpartum period. Many studies investigating the prevalence, risk factors, and impact of postpartum anovulation have used progesterone concentrations (serum or milk) or ovarian ultrasonography to determine whether the cows are cycling or not [5-7]. For those ones using progesteronemia, a common procedure in these papers is to consider cows anovular (or not cycling) if they have progesteronemia results $<1 \mathrm{ng} / \mathrm{mL}[2,5,7]$. Interestingly, the threshold of $1 \mathrm{ng} / \mathrm{mL}$ is commonly used in studies but there is little evidence to support this as the optimal progesteronemia value

for defining postpartum anovulation. In other words, it remains unclear whether the use of this threshold is associated with the subsequent reproductive performance of dairy cows. Further research should investigate the optimal progesteronemia threshold for diagnosing postpartum anovulation.

Risk factors for postpartum anovulation have been reported in previous studies; some of them relate to an increased severity of negative energy balance during the postpartum period [8,9]. Thus, elevated concentrations of serum NEFA and BHBA were associated with an increased risk of postpartum anovulation in dairy cows $[1,2]$. In a recent study, it was shown that hyperketonemic cows with low glucose concentration $(\leq 2.2 \mathrm{~m} \mathrm{~mol} / \mathrm{L})$ reacted differently to treatment than hyperketonemic cows with greater glucose concentration [10]. It would be interesting to know whether the combination of BHBA and glucose concentrations would be a risk factor for postpartum anovulation. Other reported risk factors for postpartum anovulation include reproductive tract 
diseases (metritis, endometritis), parity, season, excessive loss of body weight, and excessive length of dry period [1-3]. However, it remains unclear whether these risk factors would remain the same if the progesteronemia definition (threshold change) was modified because it is likely that it would cause some anovulation classification change. Therefore, the objectives of this study were to determine the optimal progesteronemia threshold to define postpartum anovulation and to identify risk factors for this condition in dairy cows.

\section{Materials And Methods}

Holstein lactating cows from 100 commercial dairy farms were enrolled in this cow-level observational study. The participating farms were selected in the client list of the bovine ambulatory clinic of the Faculté de médecine vétérinaire of the Université de Montréal (St-Hyacinthe, QC, Canada) and were located within $60 \mathrm{~km}$ of the clinic. These herds and cows were recruited based on convenience. This study was conducted between November 1st 2015 and October 31st 2016 and followed cows between 1 and 100DIM. An estimated sample size of 3,747 cows was targeted for the study based on a postpartum anovulation prevalence difference of 5 percentage points in cows (when presence of risk factors: $25 \%$ anovulation; when absence of risk factor: $30 \%$ anovulation, a risk factor prevalence of 33\%, and accounting for alpha and beta errors of 5 and 20\%, respectively [11]. Participating herds were visited by a veterinarian and animal health technician every $14 \mathrm{~d}$. Herds were sampled between November 1st 2015 and October 31st 2016. Cows were enrolled in the study at the time of calving. Recorded data during the study included calving date, calving season (cold season: November 1st to April 30th vs. warm season: May 1st to October 31st), parity group (1-2 vs. 3 or greater), dystocia (pull necessitating 2 people or more, a calf-jack, taking longer than $15 \mathrm{~min}$ of pulling or veterinary assisted), retained placenta (retention of fetal membranes $24 \mathrm{~h}$ after calving), twinning, and displaced abomasum (diagnosed by a veterinarian and including left and right displacement cases). All enrolled cows were sample for blood between 1 and 14DIM to quantify ketonemia (BHB) using the Precision extra device (Abbott, Mississauga, ON, Canada). A volume of $1 \mathrm{~mL}$ of blood was then collected from each cow and immediately tested with the device. The analytical sensitivity of the device was $0.2 \mathrm{mmol} / \mathrm{L}$ and its maximum value was $7.2 \mathrm{mmol} / \mathrm{L}$. Hyperketonemia was defined as a blood BHB value of $\geq 1.4 \mathrm{mmol} / \mathrm{L}$ [12].

Using the same blood sample, blood glucose was also quantified using the same Precision Xtra device, which has been validated for the quantification of BHB and glucose in dairy cattle $[13,14]$. The analytical sensitivity and maximum value of the device were $0.1 \mathrm{mmol} / \mathrm{L}$ and $5.2 \mathrm{mmol} / \mathrm{L}$, respectively. Hypoglycemia was defined as a blood glucose value of $\leq 2.2 \mathrm{mmol} / \mathrm{L}$ [10]. All cows were examined between 30 and 43 DIM for purulent vaginal discharge, cytological endometritis, and leukocyte esterase endometritis. A Metricheck device (Simcro Tech Ltd., Hamilton, NZ) was used to assess vaginal discharge. Scoring was based on: $0=$ no discharge, $1=$ clear mucus, 2 = mucus with flecks of pus, $3=$ half pus and half mucus, $4=$ purulent discharge or $5=$ foul-smelling discharge [15]. Purulent vaginal discharge was defined as a Metricheck score $\geq 4$ [16]. The cytobrush technique [17] was used to obtain a cytological sample from the body of the uterus. The microscope glass slide of every cow that was smeared with the cytobrush was brought back to the laboratory. Within $12 \mathrm{~h}$ of collection, the slide was stained using a modified Wright-Giemsa stain (Hema3, Biochemical Sciences, Swedesboro, NJ). Microscopic evaluation of all slides was performed individually at 400x magnification by one experienced observer (animal health technician). The percentage of polymorphonuclear cells was determined in two different regions of the slide using a differential count of 200 cells as previously described [16]. Cytological endometritis was defined as having $\geq 6 \%$ polymorphonuclear cells [16].

After cow-side sampling and microscope glass smearing, the cytobrush was plunged into an individual vial (3mL) containing $1 \mathrm{~mL}$ of $0.9 \%$ saline solution $(\mathrm{NaCl} 0.9 \%$ Irrigation, Baxter Corp. Mississauga, Ontario, Canada). A leukocyte esterase test was then performed on the farm, as described elsewhere [16]. In summary, the saline vial was shaken for $10 \mathrm{~s}$ and a drop of solution was put on a leukocyte esterase commercial strip (Multistix 10 SG, Bayer Corporation, Elkart, IN). Test results were read after $2 \mathrm{~min}$ according to the manufacturer's recommendations $(0=$ negative, $0.5=$ trace amount of leukocytes, 1 = small amount of leukocytes, $2=$ moderate amount of leukocytes, 3 = large amount of leukocytes). Leukocyte esterase endometritis was defined as having a score of $\geq 1$ [16]. All cows were bled between 30 and 43DIM as well as between 44 and 57 DIM (14d interval) for quantifying progesteronemia. Blood was collected into dry evacuated tubes (Vacutainer, Beckton-Dixon, Franklin Lakes and NJ) and brought back on ice to the laboratory. Samples were centrifuged within $6 \mathrm{~h}$ of collection and serum samples were extracted. They were frozen at $-20 \mathrm{oC}$ until testing at the veterinary diagnostic laboratory of the Université de Montréal (St-Hyacinthe, QC, Canada). Progesteronemia was quantified using a sequential competitive ELISA (Immulite, Siemens, Mississauga, Ontario, Canada) validated for use in cattle [18]. The inter- and intra-assay $\mathrm{CV}$ of this test were 8.9 and $6.9 \%$, respectively. All participating cows were enrolled into a systematic ovulation synchronization protocol for first service after a voluntary waiting period of $60 \mathrm{~d}$. Artificial insemination was used for all breeding. Pregnancy diagnosis was performed by transrectal palpation between 32 and $45 \mathrm{~d}$ after last insemination. Cows identified as "do not breed" after enrolment but before first service were excluded from the first service reproductive data analyses because of the lack of appropriate data. Reproductive and culling events of enrolled cows were collected until 100DIM.

\section{Statistical Analyses}

Statistical analyses were performed using SAS version 9.4 (SAS Institute Inc., Cary, NC). The experimental unit in this study 
was the cow. Dummy variables were created to test for different progesteronemia thresholds. For example, the threshold of $\leq 1 \mathrm{ng} /$ $\mathrm{ml}$ was used to dichotomize both progesteronemia values (one at 30-43 DIM and one at 44-57DIM) of each cows. The same was performed for all possible thresholds between 0.80 and $1.20 \mathrm{ng} /$ $\mathrm{mL}$ using an increment difference of $0.02 \mathrm{ng} / \mathrm{mL}$ between each threshold (e.g. 0.80, 0.82, 0.84, etc.). Cows were considered to be anovular at 50 DIM $( \pm 7)$ when progesteronemia values were below the optimal threshold at both tests (30-43 and 44-57 DIM). A preliminary screening of progesteronemia thresholds to optimally define anovulation at 50DIM was performed. Analyses in $2 \times 2$ tables were performed using the Pearson Chi-squared test (FREQ procedure) and considering success at first service as the outcome. For each progesteronemia threshold, a 2x2 table was built. Sensitivity and specificity for predicting pregnancy status was calculated for each table. The 5 thresholds with the highest combined sum of sensitivity and specificity values were retained and tested in individual logisitic regression models (GLIMMIX procedure) using success at first service as the outcome, a binomial distribution, a logit link function, and accounting for the random effect of herd. Of all the retained thresholds, the progesteronemia threshold value found with the smallest P-value was proposed to be the optimal threshold to define anovulation at 50 DIM.

Using the optimal progesteronemia threshold to define anovulation at $50 \mathrm{DIM}$, the next step was to identify risk factors. First, invariable logistic regression models (GLIMMIX procedure) considering postpartum anovulation as dependent variable and accounting for the effect of herd as a random effect were built. All the following variables were tested in invariable models: season of calving, parity group, dystocia, twinning, retained placenta, displaced abomasum, hyperketonemia, hypoglycemia, two-way interaction term of hyperketonemia and hypoglycemia, purulent vaginal discharge, cytological endometritis, and leukocyte esterase endometritis. Variables with $\mathrm{P} \leq 0.25$ were retained for building the final mixed multivariable logistic regression model (GLIMMIX procedure). That model was built using a manual backward elimination procedure until only significant variables $(\mathrm{P} \leq 0.05)$ were retained. Potential confounder variables were kept as fixed effects if their impact on the model estimates was greater than $10 \%$ [19]. Least square means of adjusted prevalence of postpartum anovulation was obtained for the retained variable of the model.

\section{Results}

A total of 3,776 cows from 100 commercial Holstein dairy herds were enrolled in this study. The participating herds had a median size of 87 lactating cows (range: 31 to 371 ). The average parity of the enrolled cows was $2.3 \pm 1.6$ (mean \pm SD) and 2077 of them (55.0\%) calved during the cold season. The proportion of cows affected by dystocia, twinning, retained placenta, displaced abomasum, purulent vaginal discharge, cytological endometritis, and leukocyte esterase endometritis during the study were $3.8 \%(145 / 3,776)$, 6.9\% (262/3,776), 6.0\% (227/3,776), 5.1\% (194/3,776), 5.5\% $(193 / 3,512), 29.3 \%(1,029 / 3,512)$, and $42.0 \%(1,475 / 3,512)$, respectively. The proportion of success at first service was $40.3 \%$ $(1,383 / 3,431)$ and the proportion of cows removed from the study (culling) at 100 DIM was $12.1 \%(457 / 3,776)$. A total of 3,512 cows were bled for progesteronemia at 30-43 DIM and 3,473 cows at 4457 DIM. Sensitivity and specificity of progesteronemia thresholds for predicting pregnancy status at first service are presented in Table 1. Mixed multivariable logistic regression models allowed to determine that the optimal progesteronemia threshold to define anovulation at 50 DIM $( \pm 7)$ was $\leq 0.90 \mathrm{ng} / \mathrm{mL}$. As such, cows with progesteronemia $\leq 0.90 \mathrm{ng} / \mathrm{mL}$ at both tests ( 37 and $50 \mathrm{DIM} \pm 7$ ) had 0.65 times the odds ( $95 \%$ confidence interval: $0.48-0.83 ; \mathrm{P}<0.01$ ) of being pregnant at first service compared with cows with greater progesteronemia.

Table 1: Sensitivity and specificity of progesteronemia thresholds for predicting pregnancy status at first service from 3,431 Holstein cows enrolled in an observational study.

\begin{tabular}{|c|c|c|c|c|c|c|}
\hline & \multicolumn{2}{|c|}{ Proportion of Pregnant Cows (\%) } & & & \\
\hline Threshold (ng/mL) & At or below threshold & Above threshold & $\mathbf{S e}^{\mathbf{a}} \mathbf{( \% )}$ & $\mathbf{S p}^{\mathbf{b}} \mathbf{( \% )}$ & $\mathbf{S e}^{\mathbf{a}}+\mathbf{S p}^{\mathbf{b}}$ & $\mathbf{P}^{\mathbf{v}} \mathbf{\text { value }}$ \\
\hline$\leq 0.80$ & 36 & 46 & 34 & 67 & 101 & 0.045 \\
\hline$\leq 0.82$ & 36 & 47 & 35 & 68 & 103 & 0.013 \\
\hline$\leq 0.84$ & 36 & 47 & 37 & 67 & 104 & 0.011 \\
\hline$\leq 0.86$ & 36 & 47 & 36 & 68 & 104 & 0.009 \\
\hline$\leq 0.88$ & 36 & 47 & 37 & 68 & 105 & 0.004 \\
\hline$\leq 0.90$ & 36 & 48 & 41 & 65 & 106 & 0.002 \\
\hline$\leq 0.92$ & 36 & 48 & 42 & 63 & 105 & 0.005 \\
\hline$\leq 0.94$ & 36 & 48 & 43 & 62 & 105 & 0.008 \\
\hline$\leq 0.96$ & 36 & 48 & 45 & 60 & 105 & 0.009 \\
\hline$\leq 0.98$ & 37 & 48 & 48 & 55 & 103 & 0.014 \\
\hline$\leq 1.00$ & 37 & 48 & 48 & 53 & 101 & 0.033 \\
\hline$\leq 1.02$ & 38 & 48 & 49 & 51 & 100 & 0.045 \\
\hline$\leq 1.04$ & 39 & 48 & 50 & 50 & 100 & 0.064 \\
\hline
\end{tabular}




\begin{tabular}{|c|c|c|c|c|c|c|}
\hline$\leq 1.06$ & 40 & 48 & 52 & 48 & 100 & 0.073 \\
\hline$\leq 1.08$ & 40 & 48 & 54 & 45 & 99 & 0.076 \\
\hline$\leq 1.10$ & 40 & 48 & 55 & 45 & 100 & 0.081 \\
\hline$\leq 1.12$ & 41 & 48 & 56 & 44 & 100 & 0.095 \\
\hline$\leq 1.14$ & 41 & 48 & 56 & 43 & 99 & 0.099 \\
\hline$\leq 1.16$ & 41 & 48 & 59 & 40 & 99 & 0.114 \\
\hline$\leq 1.18$ & 42 & 48 & 61 & 39 & 100 & 0.148 \\
\hline$\leq 1.20$ & 44 & 49 & 64 & 37 & 101 & 0.194 \\
\hline
\end{tabular}

aSensitivity; 'bpecificity

The next step was to identify risk factors for anovulation diagnosed at 50 DIM based on the aforementioned definition: having both progesteronemia tests $\leq 0.90 \mathrm{ng} / \mathrm{mL}$. On the other hand, cows were considered to be ovular if at least one or both tests had a progesteronemia $>0.90 \mathrm{ng} / \mathrm{mL}$. A dummy variable was created for that purpose. Invariable logistic regression models were built considering anovulation as the dependent variable. Variables retained for further modeling were parity group $(\mathrm{P}<0.01)$, season of calving $(\mathrm{P}<0.01)$, retained placenta $(\mathrm{P}=0.02)$, displaced abomasum
( $\mathrm{P}=0.04)$, hyperketonemia $(\mathrm{P}=0.01)$, hypoglycemia $(\mathrm{P}=0.19)$, twoway interaction term of hyperketonemia and hypoglycemia $(\mathrm{P}<0.01)$, purulent vaginal discharge $(\mathrm{P}=0.04)$, cytological endometritis $(\mathrm{P}<0.01)$, and leukocyte esterase endometritis $(\mathrm{P}<0.01)$. Variables not retained were dystocia $(\mathrm{P}=0.54)$ and twinning $(\mathrm{P}=0.68)$. A multivariable model was built using a backward elimination strategy until only significant variables remained in the model. This final model is presented in Table 2. Least square means of this final model are also presented in the same table.

Table 2: Final logistic regression model of factors associated with anovulation at 50DIM in 3,473 Holstein postpartum dairy cows enrolled in an observational study.

\begin{tabular}{|c|c|c|c|c|c|}
\hline Variable & Class & Odds Ratio & $95 \% \mathrm{CI}^{\mathrm{b}}$ & $P$ value & Anovulation $^{c}$ \\
\hline \multirow{2}{*}{ Hyperketonemia } & $<1.4 \mathrm{mmol} / \mathrm{L}$ & Referent & & & $32 \%{ }^{\mathrm{d}}$ \\
\hline & $\geq 1.4 \mathrm{mmol} / \mathrm{L}$ & 1.49 & $1.16-1.87$ & 0.02 & $45 \%$ e \\
\hline \multirow{2}{*}{ Hypoglycemia } & $\leq 2.2 \mathrm{mmol} / \mathrm{L}$ & Referent & & & $36 \%{ }^{d}$ \\
\hline & $>2.2 \mathrm{mmol} / \mathrm{L}$ & 0.98 & $0.72-1.23$ & 0.45 & $35 \% \%^{d}$ \\
\hline \multirow{4}{*}{$\begin{array}{l}\text { Hyperketonemia X } \\
\text { Hypoglycemiaf }\end{array}$} & $\begin{array}{c}\mathrm{BHB}<1.4 \mathrm{mmol} / \mathrm{L}+ \\
\text { Glucose } \leq 2.2 \mathrm{mmol} / \mathrm{L}\end{array}$ & Referent & & & $31 \%{ }^{d}$ \\
\hline & $\begin{array}{c}\mathrm{BHB}<1.4 \mathrm{mmol} / \mathrm{L}+ \\
\text { Glucose }>2.2 \mathrm{mmol} / \mathrm{L}\end{array}$ & 1.04 & $0.83-1.25$ & 0.58 & $32 \%{ }^{d}$ \\
\hline & $\begin{array}{c}\mathrm{BHB} \geq 1.4 \mathrm{mmol} / \mathrm{L}+ \\
\text { Glucose } \leq 2.2 \mathrm{mmol} / \mathrm{L}\end{array}$ & 1.85 & $1.49-2.22$ & $<0.01$ & $55 \%{ }^{e}$ \\
\hline & $\begin{array}{c}\mathrm{BHB} \geq 1.4 \mathrm{mmol} / \mathrm{L}+ \\
\text { Glucose }>2.2 \mathrm{mmol} / \mathrm{L}\end{array}$ & 1.25 & $1.02-1.46$ & 0.04 & $42 \%{ }^{d}$ \\
\hline \multirow{2}{*}{ Parity group } & $\leq 2$ & Referent & & & $29 \%{ }^{d}$ \\
\hline & $>2$ & 1.64 & $1.39-2.00$ & $<0.01$ & $48 \% \%^{\mathrm{e}}$ \\
\hline \multirow{2}{*}{ Season of calving } & $\begin{array}{c}\text { Warm (May to } \\
\text { October) }\end{array}$ & Referent & & & $30 \%{ }^{d}$ \\
\hline & $\begin{array}{c}\text { Cold (November to } \\
\text { April) }\end{array}$ & 1.32 & $1.06-1.72$ & 0.03 & $40 \%{ }^{\mathrm{e}}$ \\
\hline \multirow{2}{*}{$\begin{array}{c}\text { Cytological } \\
\text { endometritis }\end{array}$} & $<6 \% \mathrm{PMN}^{g}$ & Referent & & & $28 \%^{\mathrm{d}}$ \\
\hline & $\geq 6 \% \mathrm{PMN}^{\mathrm{g}}$ & 1.42 & $1.25-1.59$ & $<0.01$ & $40 \%{ }^{\mathrm{e}}$ \\
\hline
\end{tabular}

${ }^{\text {aProgesteronemia }} \leq 0.90 \mathrm{ng} / \mathrm{mL}$ at both tests performed at 30-43 and 44-57 DIM

b95\% confidence interval

'Least square means; anovulation at 50 days in milk is defined as progesteronemia $\leq 0.90 \mathrm{ng} / \mathrm{mL}$. Within each variable, different superscript letters ${ }^{(\mathrm{d}, \mathrm{e})}$ indicate a significant $(\mathrm{P} \leq 0.05)$ difference.

${ }^{\mathrm{f}}$ Two-way interaction term.

gPolymorphonuclear cells. 


\section{Discussion}

The results of the current study showed that the optimal threshold for defining anovulation at 50 DIM $( \pm 7)$ is $\leq 0.90 \mathrm{ng} / \mathrm{mL}$ when samples are collected twice at a $14 \mathrm{~d}$ interval. This threshold is different from $\leq 1 \mathrm{ng} / \mathrm{mL}$ commonly used in studies using progesteronemia to determine if cows are anovular or not $[2,5,7]$. The optimal threshold reported in the present study is based on an objective definition by finding the cut-off that provides the highest sum of sensitivity and specificity to predict pregnancy status at first service. Such approach has been used in many other studies $[12,20,21]$ and is considered to be a scientifically valid technique [22]. Other commonly used methods to diagnose anovulation are to quantify progesterone in milk $[1,6]$ or to perform ultrasonographic measurements of the ovaries [4]. It remains unclear what thresholds (progesterone concentration for example) would be optimal if a similar approach to the current study was used. Future research should address this point. Future research should also address if the use of other blood progesterone tests (such as radial immunoassay) would provide similar results to ones reported in the current study (ELISA).

Risk factors for anovulation at 50 DIM identified in the present study was relatively similar to other studies. For example, it was not surprising that season, parity group, and cytological endometritis were found in the final statistical model, as they had been reported previously $[2,7,23]$. Interestingly, the two-way interaction term of hyperketonemia and hypoglycemia was significant in the final model. The least square means showed cows that were simultaneously hyperketonemic ( $\geq 1.4 \mathrm{mmol} / \mathrm{L})$ and hypoglycemic ( $\leq 2.2 \mathrm{mmol} / \mathrm{L}$ ) had a much greater occurrence of postpartum anovulation than all other groups of cows. This finding is novel and highlights the growing interest to further investigate this subpopulation of cows. It has already been shown that these cows react differently to treatments compared with hyper ketonemic cows that are normoglycemic [10]. It can be speculated that these cows experience a different and probably more severe period of negative energy balance, which could explain why they are more likely to remain anovular for a long period of time.

Because of the expected high collinearity between cytological endometritis and leukocyte esterase endometritis variables, it was a priori decided during the final model building to only retain one of them. As leukocyte esterase endometritis diagnosis is performed on farms as a convenient cow-side proxy test for cytological endometritis, it made more sense that the latter be offered to the final model. However, on-farm users of leukocyte esterase endometritis diagnostic test should keep in mind that this test was associated with postpartum anovulation in invariable models and therefore might be considered for postpartum disease management as a potential risk factor for postpartum anovulation. In conclusion, based on providing the highest sum of sensitivity and specificity to predict pregnancy status at first service, the optimal progesteronemia threshold to define anovulation at 50 DIM was $\leq 0.90 \mathrm{ng} / \mathrm{mL}$. Animals at greater risk for this disease included cows with parity $\geq 2$, cows with cytological endometritis, cows that calved during the cold season (November to April), and cows that were simultaneously hyperketonemic and hypoglycemic during the first two weeks postpartum.

\section{References}

1. Walsh RB, Kelton DF, Duffield TF, Leslie KE, Walton JS, et al. (2007) Prevalence and risk factors for postpartum anovulatory condition in dairy cows. J Dairy Sci 90(1): 315-324.

2. Dubuc J, Duffield TF, Leslie KE, Walton JS, LeBlanc SJ (2012) Risk factors and effects of postpartum anovulation in dairy cows. J Dairy Sci 95(4): 1845-1854.

3. Vieira-Neto A, Gilbert RO, Butler WR, Santos JE, Ribeiro ES et al. (2014) Individual and combined effects of anovulation and cytological endometritis on the reproductive performance of dairy cows. J Dairy Sci 97(9): 5415-5425.

4. Galvão K, Frajblat M, Butler W, Brittin S, Guard C, et al. (2010) Effect of Early Postpartum Ovulation on Fertility in Dairy Cows. Reprod Dom Anim 45(5): e207-e211.

5. Stevenson JS, Pursley JR, Garverick HA, Fricke PM, Kesler DJ, et al. (2006) Treatment of cycling and non-cycling lactating dairy cows with progesterone during ovsynch. J Dairy Sci 89(7): 2567-2578.

6. Gautam G, Nakao T, Yamada K, Yoshida C (2010) Defining delayed resumption of ovarian activity postpartum and its impact on subsequent reproductive performance in Holstein cows. Theriogenology 73(2): 180189.

7. Vercouteren MM, Bittar JH, Pinedo PJ, Risco CA, Santos JE, et al. (2015) Factors associated with early cyclicity in postpartum dairy cows. J Dairy Sci 98(1): 229-239.

8. Beam SW, Butler WR (1998) Energy balance, metabolic hormones, and early postpartum follicular development in dairy cows fed prilled lipid. J Dairy Sci 81(1): 121-131.

9. Beam SW, Butler WR (1999) Effects of energy balance on follicular development and first ovulation in postpartum dairy cows. J Reprod Fertil 54: 411-424.

10. Gordon JL, Duffield TF, Herdt TH, Kelton DF, Neuder L, et al. (2017) Effects of a combination butaphosphan and cyanocobalamin product and insulin on ketosis resolution and milk production. J Dairy Sci 100(4): 2954-2966.

11. Dohoo I, Martin W, Stryhn H (2003) Veterinary Epidemiologic Research. 1st ed. Charlottetown, Prince-Edward-Island: VER Inc: 39-45.

12. Duffield TF, Lissemore KD, McBride BW, Leslie KE (2009) Impact of hyperketonemia in early lactation dairy cows on health and production. J Dairy Sci 92(2): 571-580.

13. Iwersen M, Falkenberg U, Voigtsberger R, Forderung D, Heuwieser W (2009) Evaluation of an electronic cow-side test to detect subclinical ketosis in dairy cows. J Dairy Sci 92(6): 2618-2624.

14. Wittrock JA, Duffield TF, LeBlanc SJ (2013) Validation of a point-of-care glucometer for use in dairy cows. J Dairy Sci 96(7): 4514-4518.

15. McDougall S, Macaulay R, Compton C (2007) Association between endometritis diagnosis using a novel intravaginal device and reproductive performance in dairy cattle. Anim Reprod Sci 99(1-2): 9-23.

16. Denis Robichaud J, Dubuc J (2015) Determination of optimal diagnostic criteria for purulent vaginal discharge and cytological endometritis in dairy cows. J Dairy Sci 98(10): 6848-6855. 
17. Kasimanickam R, Duffield TF, Foster RA, Gartley CJ, Leslie KE, et al. (2004) Endometrial cytology and ultrasonography for the detection of subclinical endometritis in postpartum dairy cows. Theriogenology 62(1-2): 9-23.

18. Martin JL, Vonnahme KA, Adams DC, Lardy GP, Funston RN (2007) Effects of dam nutrition on growth and reproductive performance of heifer calves. J Anim Sci 85(3): 841-847.

19. Maldonado G, Greenland S (1993) Simulation study of confounderselection strategies. Am J Epidemiol 138(11): 923-936.

20. Dubuc J, Duffield TF, Leslie KE, Walton JS, LeBlanc SJ (2010) Definitions and diagnosis of postpartum endometritis in dairy cows. J Dairy Sci 93(11): 5225-5233.
21. Roberts T, Chapinal N, LeBlanc SJ, Kelton DF, Dubuc J, Duffield TF (2012) Metabolic parameters in transition cows as indicators for early-lactation culling risk. J Dairy Sci 95(6): 3057-3063.

22. de Boer MW, LeBlanc SJ, Dubuc J, Meier S, Heuwieser W, et al. (2014) Invited review: Systematic review of diagnostic tests for reproductivetract infection and inflammation in dairy cows. J Dairy Sci 97(7): 39833999.

23. Senosy WS, Uchiza M, Tameoka N, Izaike Y, Osawa T (2009) Association between evaluation of the reproductive tract by various diagnostic tests and restoration of ovarian cyclicity in high-producing dairy cows. Theriogenology 72(9): 1153-1162.

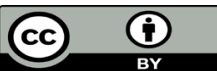

This work is licensed under Creative Commons Attribution 4.0 License

Submission Link:

Submit Article

DOI: $10.32474 / C D V S .2018 .01 .000115$

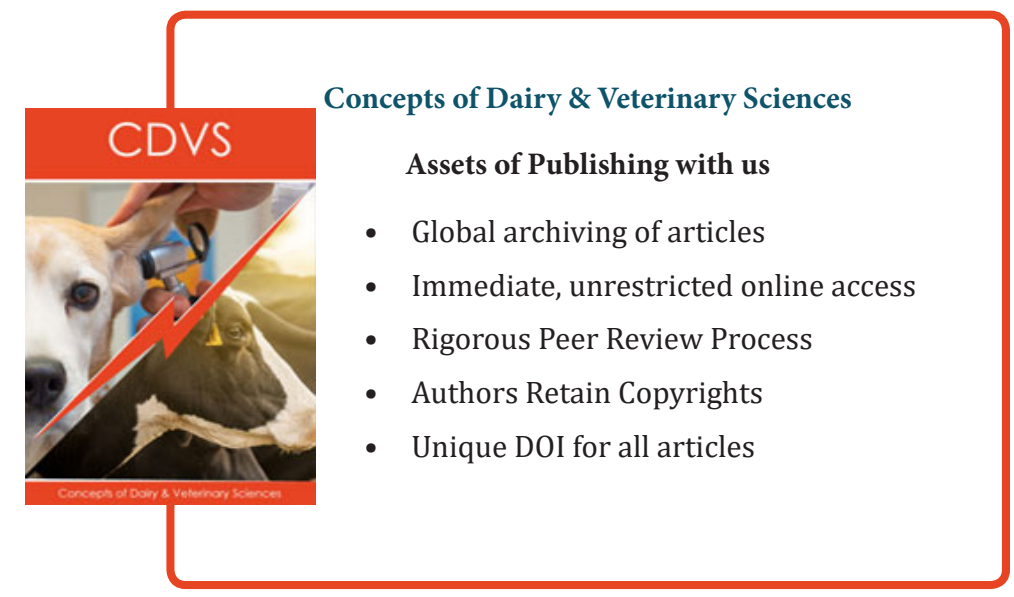

